\title{
Hydrological properties of litter layers in mixed forests in Mt. Qinling,
}

\section{China}

\author{
Shujun Chen ${ }^{(1-2)}$, \\ Tianjian $\mathrm{CaO}^{(1)}$, \\ Nobuaki Tanaka ${ }^{(3)}$, \\ Tian Gao ${ }^{(1)}$, \\ Lan Zhu ${ }^{(4)}$, \\ Chris B Zou ${ }^{(3-5-6)}$
}

\begin{abstract}
The litter layer is an important component of forest ecosystems, although little is known about the differences in litter characteristics and hydrological properties of unmanaged, overgrown broadleaved and coniferous mixed forests in the subtropical and temperate zones. This study was carried out in a naturally generated broadleaved and coniferous mixed forest at the Qinling National Forest Ecosystem Research Station, Shaanxi Province, China. We quantified the litter thickness, mass, and its hydrological properties in evergreen pine (Pinus tabulaeformis) stands and deciduous oak (Quercus aliena var. acuteserrata) stands through in situ surveys and laboratory immersion experiments. The thickness of the litter layer for $P$. tabulaeformis averaged 9.3 $\pm 2.8 \mathrm{~cm}$, and it was not significantly different from that detected in the $Q$. aliena stand $(8.3 \pm 3.6 \mathrm{~cm})$. The total mass of the litter layer for $P$. tabulaeformis, $27.94 \pm 9.81 \mathrm{Mg} \mathrm{ha}^{-1}$, was significantly higher than the total mass of $16.04 \pm 3.60 \mathrm{Mg} \mathrm{ha}^{-1}$ found for $Q$. aliena. The mass of the semi-decomposed, fermented litter (OF) layer was significantly higher than that of the non-decomposed litter (OL) layer, irrespective of species. The rate of water absorption by dry litter was the highest at the onset of the immersion experiment and decreased exponentially with time. The water-holding capacity $\left(W_{m}\right)$ and water-interception capacity $\left(W_{i}\right)$ of the OF layer were higher than the OL layer for both forest stands. The $W_{\mathrm{m}}$ and $W_{\mathrm{i}}$ for the $P$. tabulaeformis stand were higher than those for the $Q$. aliena stand at our study sites. The higher $W_{\mathrm{m}}$ and $W_{i}$ for $P$. tabulaeformis may be more effective in ameliorating the splash impact from high-intensity storms to improve water quality, while relatively lower $W_{\mathrm{m}}$ and $W_{\mathrm{i}}$ for $Q$. aliena may be considered favorable for augmenting water yield. Forest resource managers should consider those differences along with the other components of the water budget when making management decisions.
\end{abstract}

Keywords: Water Conservation Forest, Hydrological Properties, Forest Succession

overgrown forests on water resource management in humid regions has been underappreciated in locations where water scarcity is less pressing compared with semiarid and arid regions (Gallart \& Llorens 2003, Gomyo \& Kuraji 2016). The litter layer

\section{Introduction}

Many natural forests and plantations have become overgrown during the past few decades, and this is a global phenomenon (Llorens et al. 1997, Zou et al. 2008, Kuraji 2012, Sun et al. 2014). The implication of is an important component of forest ecosystems and its importance is often underestimated in water resource management (Schaap et al. 1997, Levia et al. 2005, llek et al. 2015). More recent studies have added evidence of a substantial impact of litter on the water budget in semiarid shrubland and woodland with a substantial litter layer (Dunkerley 2000, Chang et al. 2008, Bulcock \& Jewitt 2012, Acharya et al. 2017). However, the litter production dynamics, litter layer structure and hydrological properties of secondary forests in humid forest ecosystems, as well as their relevance in water conservation management have not been widely studied. With the increasing acreage of secondary forests and overgrown plantations in subtropical and temperate forest systems, the quantity and quality of ecosystem services provided by those forest stands deserve further studies.

Forest litter, a sponge layer separating precipitation from mineral soil, mediates rainfall splash impact and reduces, delays or often eliminates overland flow and soil erosion from the forest floor (Gao \& Zhou 


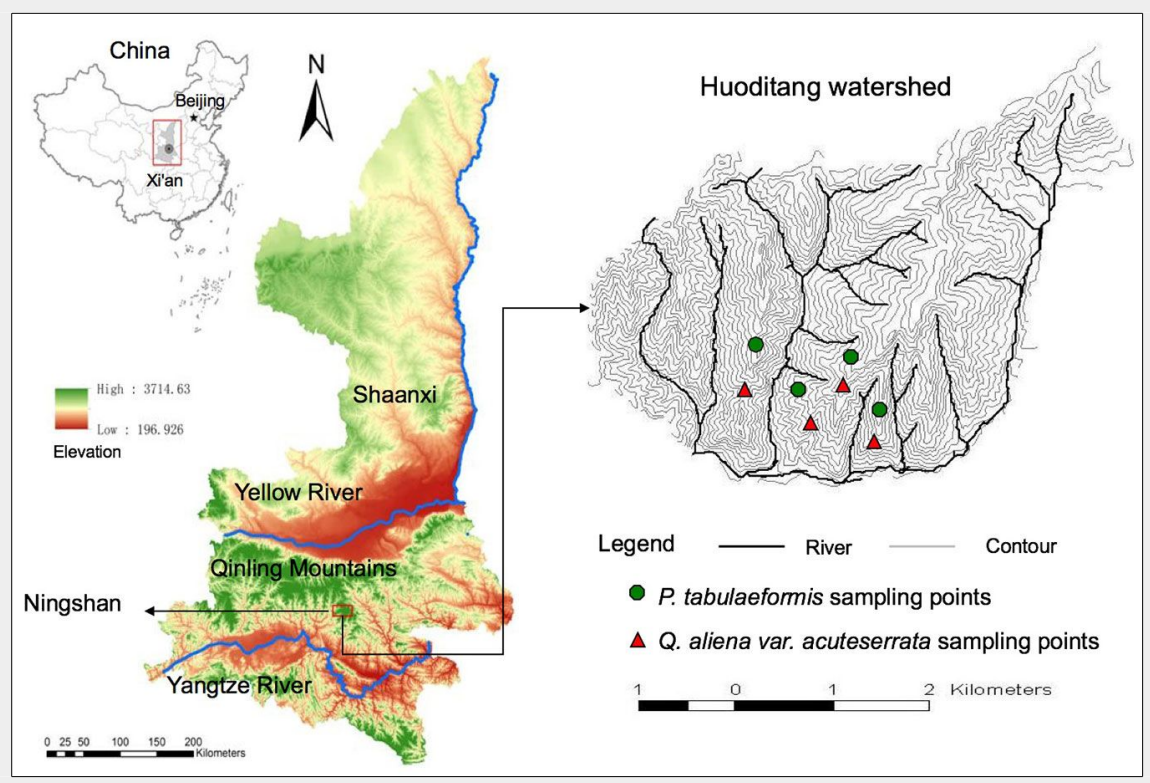

Fig. 1 - Geographic location of study site and spatial distribution of sampling points in the Huoditang Watershed, located in the Qinling National Forest Ecosystem Research Station (southern Qinling Mountains, central China, 161 km south of Xian City).

2002, Neris et al. 2013). As a result, the amount of litter and its hydrological properties in a forested catchment could affect not only the water quality but also the water yield of the catchment. A recent study on Japanese red pine (Pinus densiflora) and konara oak (Quercus serrata) mixed forest in Japan (Gomyo \& Kuraji 2016) demonstrated that the litter layer plays an important role in the hydrological cycle of humid ecosystems, and litter removal resulted in the increase of peak flow, particularly during relatively large flood events. However, we know little about the differences in litter characteristics and hydrological properties between broadleaved species and coniferous species in the mixed forests of the subtropical and temperate zones. Such information is particularly useful from the perspective of managing water conservation forests for water yield and water quality (Sato et al. 2004, Komatsu \& Rappleye 2017).

The Qinling Mountains are the highest mountain range in central and eastern China, with an east-west length of $1600 \mathrm{~km}$ and a north-south width ranging from tens to two-three hundred kilometers. They divide the Yangtze River system to the south and the Yellow River system to the north, and are located in the central and southern part of Shaanxi Province between the Wei River and the Han River. The forest area encompasses gullies, ravines, and streams, and contains abundant water resources reaching a total amount of 22.2 billion $\mathrm{m}^{3}$ (Wen 2011). The southern slope of the Qinling Mountains has a water resource amount of approximately 18.2 billion $\mathrm{m}^{3}$ and is an important recharge source for the Danjiangkou Reservoir, the headwater source of the central route of China's South to North Water Diversion Project
(SNWDP - Wen 2011). The average annual streamflow into the reservoir was reported to have substantially decreased in past decades (Liu et al. 2012).

The southern slope of the Qinling Mountains is co-dominated by P. tabulaeformis and Quercus aliena var. acuteserrata (Q. aliena, hereafter) between 1300 and 1800 $\mathrm{m}$ a.s.l. of elevation. A 30-year-old study quantified the litter characteristics of young and middle-aged $P$. tabulaeformis and Q. aliena forests (Lei 1984). Currently, most of those forests have become overgrown due to lack of management. A recent study revealed that the streamflow in this region decreased during the same period as a result of the reduced precipitation, though $10-15 \%$ of such decrease was attributed to non-climate related causes, including vegetation (Liu et al. 2012). Nonetheless, there have been no studies on the characteristics and hydrological properties of the litter layer of these forests, especially on possible differences between $P$. tabulaeformis and Q. aliena (the dominant species in the area) stands in favoring water resource management.

In this study, we quantified the thickness, mass, and hydrological properties of the litter layer in representative Pinus tabulaeformis and Quercus aliena stands through in situ site surveys and laboratory immersion experiments, with the aim of providing data support and theoretical guidance to water resource management and conservation in the Qinling Mountains.

\section{Materials and methods}

\section{Study site}

The study was carried out in the Huoditang Watershed at the Qinling National Forest Ecosystem Research Station at
Ningshan County, Shaanxi Province, China $\left(33^{\circ} 18^{\prime} \mathrm{N}, 108^{\circ} 20^{\prime} \mathrm{E}\right.$ - Fig. 1). The station is located on the southern slope of the Qinling Mountains, falling within the transition zone of the warm-temperate deciduous broadleaved forest region and the subtropical evergreen broadleaved forest region (Pan et al. 2003). The elevation ranges from 800 to $2474 \mathrm{~m}$ a.s.l., declining from east to west. The topography is diverse with mainly southwestward slopes ranging from $20^{\circ}$ to $50^{\circ}$. The average annual temperature ranges from 8 to $10{ }^{\circ} \mathrm{C}$ The average annual precipitation ranges from 900 to $1200 \mathrm{~mm}$, with rainfall mostly occurring from May to October and snowfall occurring from November to the beginning of April. The average annual evaporation reaches 800 to $950 \mathrm{~mm}$ (Chen et al. 2013). The soil at this site belongs to mountain brown soil, and the bedrock mainly consists of granite, gneiss, metamorphic sandstone and schist (Zhang \& Liang 2012). The study site is primarily covered by naturally regenerated, secondary forests. Distinct zoning in forest types exists along an elevation gradient, with the deciduous broadleaved forest distributed at the bottom, coniferous and broad-leaved mixed forest in the middle, and subalpine coniferous forest on the top. In this study, we focused on the $P$. tabulaeformis stands and Q. aliena stands forming the coniferous and broadleaved mixed forest at the altitudes ranging from 1300 to $1800 \mathrm{~m}$ a.s.l. These stands were primarily naturally regenerated after forest harvesting during the 1960 s and the 1970s. For the P. tabulaeformis stand, the associated tree species were Pinus armandi, Toxicodendron vernicifluum, Carya cathayensis Sarg, and Sorbus folgneri. The shrub layer included Viburnum dilatatum, Stachyurus chinensis, Rosa omeiensis, Lonicera hispida Pall; and the herbaceous layer contained Carex lanceolata and Stellaria media. For the Q. aliena stand, the associated tree species included $P$. tabulaeformis, Acer davidii, Carpinus cordata, Quercus aliena, P. armandi, Acer maximowiczii, and Toxicodendron vernicifluum; the shrub layer was dominated by Rosa multiflora, Lespedeza bicolor, Abelia dielsii, Spiraea fritschiana, Euonymus alatus, and Corylus heterophylla; and the herbaceous layer included Thalictrum aquilegifolium, Anemone tomentosa, Dryopteris chinensis, and Carex duriuscula sp. stenophylloides.

\section{Litter collection}

We selected four $P$. tabulaeformis sites and four Q. aliena sites that were representative of the overall stand age and growth condition, located in areas away from the road and relatively free of human disturbance. At each site, a section or an entire surface of a slope was selected following the protocol of "Observation Methodology for Long-term Forest Ecosystem Research" of the National Standards of the People's Republic of China (GB/T 33027-2016). The basic site and stand information are pre- 
sented in Tab. 1. For each site, upper, middle, and lower positions were selected. Two $0.5 \times 0.5 \mathrm{~m}$ quadrats were randomly selected for each slope position for litter sampling. Intact litter layers were collected and the un-decomposed litter (OL layer) and semi-decomposed litter (OF layer) were packed separately into plastic litter bags following the method described in the aforementioned protocol. A total of 96 litter bags $(2$ species $\times 4$ sites $\times 3$ slope positions $\times 2$ random quadrats $\times 2$ litter layers) were collected. Eight points around each quadrat were randomly selected to measure the average thickness of both $\mathrm{OL}$ and OF layers representing that quadrat. Litter bags were sealed and brought back to the laboratory to determine the fresh mass. After fresh mass determination, litter was left to air dry in the lab. Dry mass was determined by drying the air-dry samples in an oven at $85^{\circ} \mathrm{C}$ for 12 hours. Collection of litter samples was conducted after all deciduous trees dropped their leaves in November and December of 2013.

\section{Laboratory analyses}

One sub-sample from each air-dried litter bag was used to compare the litter composition by separating the litter into leaves, needles, branches, cones and herbaceous components for both P. tabulaeformis and $Q$. aliena stands. Then, one sub-sample from the air-dried litter bags for each site and slope position ( $n=12$ per species and litter horizon) was packed into porous nylon bags of known mass and weighed to calculate the corresponding gross dry litter mass $\left(m_{0}\right)$ of each sample. The nylon bags were immersed in a water bath for a predetermined time and then taken out at fixed time intervals and re-weighed to determine the gross wet mass of litter $\left(m_{i}\right)$ after full drainage. The water-holding ratio of litter $\left(R_{\mathrm{i}}, \mathrm{kg} \mathrm{kg}^{-1}\right)$ was calculated as the ratio between the total water held in the litter tissue and the dry litter mass using the following formula (eqn. 1):

$$
R_{i}=\frac{\left(m_{i}-m_{0}\right)}{m_{0}}
$$

where $R_{\mathrm{i}}$ is the water-holding capacity of litter at the immersion time $i(i=0.5,1,2,4$, $6,8,10,12$ and $24 \mathrm{~h}$ ), $\mathrm{m}_{\mathrm{o}}$ is the dry litter mass and $m_{i}$ is the litter mass at the immersion time $i$ after free drainage.

The litter water-holding capacity $\left(R_{\mathrm{m}}\right)$ was defined as the highest ratio achieved when the increase of wet mass of litter was negligible with increased immersion time. In this study, the water-holding ratio rarely increased after litter was immersed in water for $24 \mathrm{~h}$, thus $R_{m}$ was numerically equivalent to the $R_{24}$.

The total water retention capacity of the litter layer $\left(W_{m}, M g ~ h a^{-1}\right)$ in a given stand was calculated on the unit area basis using the following formula (eqn. 2):

$$
W_{m}=M \cdot R_{m}
$$

Tab. 1 - Basic characteristics of the sampling sites.

\begin{tabular}{llcc}
\hline \multirow{2}{*}{ Characteristics } & Variable & \multicolumn{2}{c}{ Vegetation type } \\
\cline { 3 - 4 } & & P. tabulaeformis & $\begin{array}{c}\text { Q. aliena var. } \\
\text { acuteserrata }\end{array}$ \\
\hline Topography & Elevation $(\mathrm{m})$ & $1542-1774$ & $1423-1752$ \\
& Slope aspect & $\mathrm{S}, \mathrm{SW}$ & $\mathrm{S}, \mathrm{SW}$ \\
& Slope $\left({ }^{\circ}\right)$ & $25-35$ & $32-40$ \\
Stands & Height $(\mathrm{m})$ & $23.35 \pm 3.04$ & $17.33 \pm 1.82$ \\
characteristics & DBH $(\mathrm{cm})$ & $23.62 \pm 1.94$ & $25.36 \pm 2.30$ \\
& Age $(\mathrm{yrs})$ & $51-65$ & $51-65$ \\
& Canopy density (\%) & $0.85-0.90$ & $0.80-0.85$ \\
\hline
\end{tabular}

where $M$ is the unit litter mass ( $M g$ ha ${ }^{-1}$ ).

Assuming the water-holding ratio of litter under ambient conditions is $R_{0}$, the maximum water interception capacity of litter $\left(\mathrm{W}_{\mathrm{i}}, \mathrm{Mg} \mathrm{ha}^{-1}\right)$ was calculated as (eqn. 3 ):

$$
R_{0}=\frac{\left(m_{1}-m_{0}\right)}{m_{0}}
$$

where $R_{0}$ is the water-holding capacity of the litter under ambient conditions, $m_{1}$ is the fresh litter mass and $m_{0}$ is the dry litter mass (eqn. 4):

$$
W_{i}=\left(R_{m}-R_{0}\right) \cdot M
$$

\section{Data analysis and statistics}

We treated tree species (P. tabulaeformis and Q. aliena) and the litter layers (OL and OF) as fixed factors, the site (four representatives for each species) as a random factor, and the slope position (lower, middle and upper) was nested under each site. Linear mixed-effects models were fitted to explore the effects of these factors and their interactions on the litter thickness and mass of the OL layer and OF layer using the "ImerTest" package in R (version 3.4.2). We also fitted models with the total thickness and total mass of the OL layer and the OF layer combined. To check the model assumptions, we applied the normality test as well as the test of equal variance of the residuals for each model. A logarithm transformation was applied to the total thickness of litter since the original data failed the normality test. For the hydrological properties determined in the laboratory, a Student's $t$-test $(\alpha=0.05)$ was performed.

\section{Results}

Litter composition, thickness and mass

The thickness differed significantly between the OL layer and the OF layer ( $p=$ $0.001)$ and this difference depended on the tree species $(p<0.001)$. There was a significant difference in litter mass between tree species and litter layer $(p<0.001)$. The total thickness of both OL and OF layers was not significantly different between tree species $(p=0.3178)$, but different tree species did significantly differ in total mass of either OL and OF layers ( $p<0.001-$ Tab. 2). The composition of the litter layer and the defoliation period of P. tabulaeformis and Q. aliena are presented in Tab. 3. The collected litter is mainly composed of leaves or needles. The needles of $P$. tabulaeformis fall both during early spring and later autumn, while the leaves of Q. aliena fall mostly during the autumn. The thickness of
Tab. 2 - F-statistics from factorial ANOVA to assess tree species ( $P$. tabulaeformis and Q. aliena var. acuteserrata), litter layer (OL and OF) and slope position (lower, middle and upper) effects on the litter thickness, mass, total litter thickness and total litter mass. (df): degrees of freedom; (SS): sum of squares; (MS): mean square; (ns): $p>$ $0.05 ;(*): p<0.05 ;(* *): p<0.01 ;(* *): p<0.001$

\begin{tabular}{lllrrrl}
\hline Variable & Factor & df & \multicolumn{1}{c}{ SS } & MS & F-value & P-value \\
\hline Litter thickness & Species & 1,42 & 2.8 & 2.8 & 0.367 & $0.3671^{\text {ns }}$ \\
& Litter layer & 1,42 & 41.44 & 41.44 & 0.001 & $0.001^{* *}$ \\
& Slope position & 2,42 & 0.34 & 0.34 & 0.951 & $0.9512^{\text {ns }}$ \\
& Species $\times$ Litter layer & 1,42 & 85.86 & 85.86 & 0 & $<0.0001^{* * *}$ \\
Litter mass & Species & 1,39 & 9.24 & 9.24 & 36.64 & $<0.0001^{* * *}$ \\
& Litter layer & 1,39 & 3.44 & 3.44 & 13.63 & $0.0006^{* * *}$ \\
& Slope position & $2,7.7$ & 1.14 & 0.57 & 2.27 & $0.1669^{\text {ns }}$ \\
& Species $\times$ Litter layer & 1,39 & 0.47 & 0.47 & 1.89 & $0.1767^{\text {ns }}$ \\
\hline \multirow{2}{*}{ Log (Total litter } & Species & 1,20 & 0.164 & 0.164 & 1.04 & $0.3178^{\text {ns }}$ \\
thickness) & Slope position & 2,20 & 0.013 & 0.006 & 0.04 & $0.9591^{\text {ns }}$ \\
\hline Total mass & Species & 1,17 & 851.09 & 851.09 & 27.32 & $<0.0001^{* * *}$ \\
& Slope position & $2,6.43$ & 119.91 & 59.96 & 1.92 & $0.221^{\text {ns }}$ \\
\hline
\end{tabular}


Tab. 3 - Composition of the litter layer and defoliation period of P. tabulaeformis and Q. aliena var. acuteserrata.

\begin{tabular}{llcc}
\hline \multirow{2}{*}{ Characteristics } & \multicolumn{2}{c}{ Vegetation type } \\
\cline { 2 - 4 } & P. tabulaeformis & $\begin{array}{c}\text { Q. aliena var. } \\
\text { acuteserrata }\end{array}$ \\
\hline Woody litter & Leaf (\%) & 86.1 & 93.4 \\
& Branch (\%) & 10.8 & 4.6 \\
& Cone, seed scale, others (\%) & 2.7 & 1.5 \\
Shrub and herb litter (\%) & 0.4 & 0.5 \\
\hline Defoliation period & Mar. to Apr., & Sep. to Nov. \\
& Nov. to Dec. & \\
\hline
\end{tabular}

the OF of $P$. tabulaeformis stand was $5.1 \pm$ $1.5 \mathrm{~cm}$ (mean \pm standard deviation), slightly larger than the $4.2 \pm 1.4 \mathrm{~cm}$ thickness of its $\mathrm{OL}$. The OF of Q. aliena was $1.9 \pm 1.2 \mathrm{~cm}$, significantly lower than the $6.4 \pm 2.7 \mathrm{~cm}$ thickness of its OL $(p=0.001)$. The combined depth of the OF and OL (total litter mass, TLL) of P. tabulaeformis was $9.3 \pm 2.8 \mathrm{~cm}$, not significantly different from the $8.3 \pm$ $3.6 \mathrm{~cm}$ depth of Q. aliena (Fig. 2a). The mass of the $P$. tabulaeformis litter layer was $27.94 \pm 9.81 \mathrm{Mg} \mathrm{ha}^{-1}$, significantly higher than the $16.04 \pm 3.60 \mathrm{Mg} \mathrm{ha}^{-1}$ mass of the Q. aliena litter layer ( $p=0.001$ - Fig. $2 b$ ). The mass of the OF layer was higher than the mass of the OL layer in both stand types (Fig. 2b). The mass of the OF layer was $16.74 \pm 6.36 \mathrm{Mg} \mathrm{ha}^{-1}$ for P. tabulaeformis, accounting for $59.85 \pm 8.46 \%$ of the total litter mass, and $8.98 \pm 3.23 \mathrm{Mg}^{-1}$ har $^{-1}$ Q. aliena, accounting for $55.49 \pm 14.43 \%$ of the total litter mass.

\section{Water-holding capacity of litter}

After one hour of water immersion, the water-holding ratio of $\mathrm{OL}$ and OF reached $74.30 \%$ and $61.61 \%$ of their holding capacity in $P$. tabulaeformis, respectively, while it was $67.26 \%$ and $91.26 \%$ in Q. aliena, respectively. The relationship between the waterholding ratio of $\mathrm{OL}$ and the time immersion in the water was fitted to a logistic model
(Fig. 3a). This relationship was similar between the two types of litter. The waterholding ratio was relatively higher for OF compared to the $\mathrm{OL}$ at the same immersion time. However, the water-holding ratio of the OF of Q. aliena did not increase substantially with an increase in the time of water immersion (Fig. 3b) and was mostly lower than the OF of $P$. tabulaeformis.

\section{Litter water-absorption rate}

The water-absorption rates of undecomposed and semi-decomposed litter layer were highest at the beginning of the experiment and declined quickly in the first 4 hours. The rate slowed down during the time interval of 4-8 $\mathrm{h}$, and was nearly unchanged after $8 \mathrm{~h}$ (Fig. 4). The water-absorption rate of the OL was $2.99 \mathrm{~kg} \mathrm{~kg}^{-1} \mathrm{~h}^{-1}$ and $2.89 \mathrm{~kg} \mathrm{~kg}^{-1} \mathrm{~h}^{-1}$ for P. tabulaeformis and Q. aliena, respectively, at the first $0.5 \mathrm{~h}$ (Fig. 4a). The water-absorption rate of the OF was $5.80 \mathrm{~kg} \mathrm{~kg}^{-1} \mathrm{~h}^{-1}$ and $6.39 \mathrm{~kg} \mathrm{~kg}^{-1} \mathrm{~h}^{-1}$ for $P$. tabulaeformis and $Q$. aliena, respectively (Fig. 4b). There were no observable differences in water-absorption rates between P. tabulaeformis and Q. aliena at the same time of water immersion.

\section{$R_{m}, W_{m}$ and $W_{i}$}

The litter water-holding capacity $\left(R_{\mathrm{m}}\right)$ of the OL was $199.45 \pm 22.83 \%$ for P. tabulae-
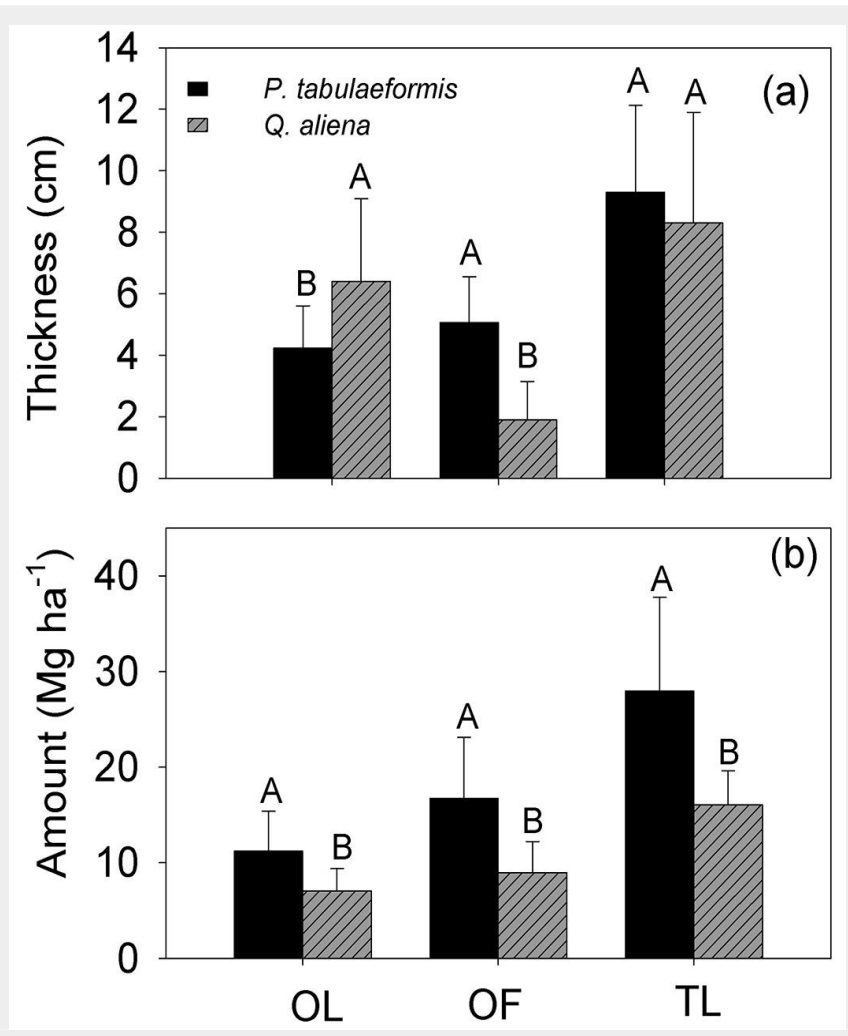

Fig. 2 - Comparison of the mean thickness and masses of the non-decomposed litter layer (OL), the semi-decomposed litter layer (OF), and the total litter (TL) of P. tabulaeformis and Q. aliena var. acuteserrata. The vertical bar represent the standard error $(n=12)$. For each category, different capital letters indicate a significant difference in the mean value between the two species.

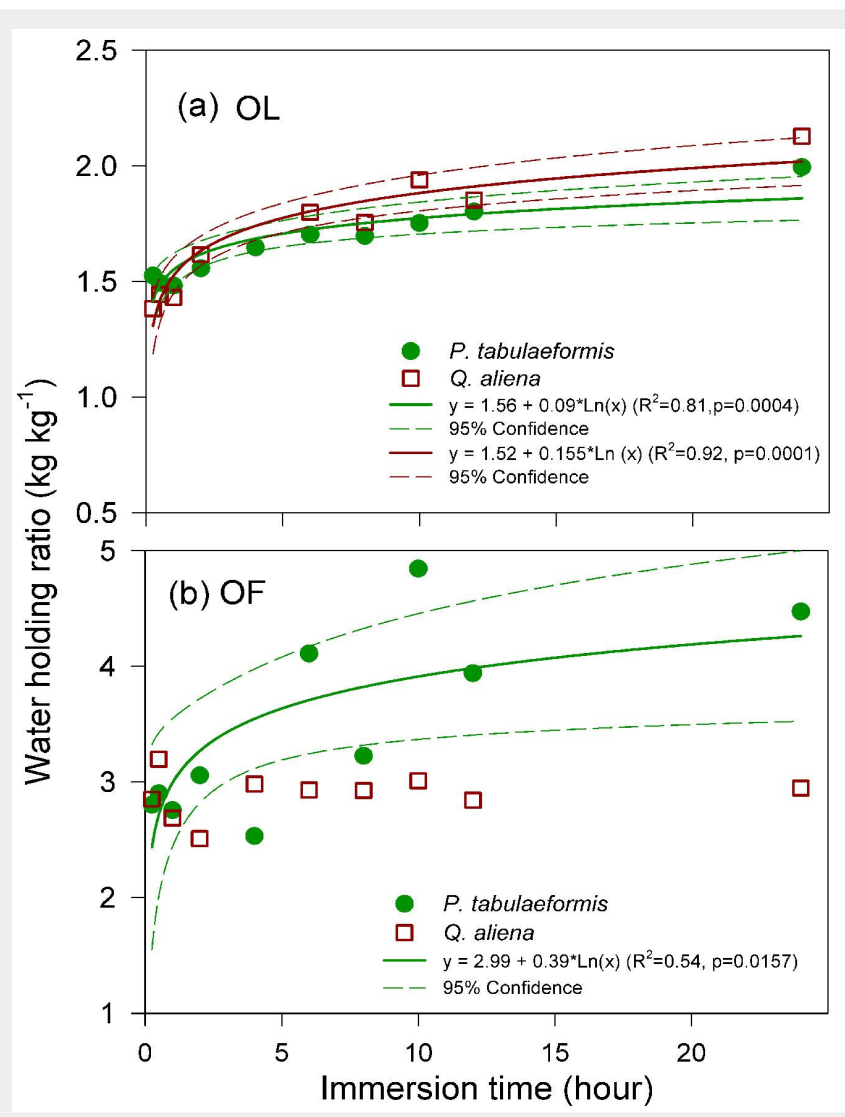

Fig. 3 - Relationships between the water-holding ratio and the immersion time of (a) non-decomposed litter (OL) and (b) semi-decomposed litter (OF) collected from P. tabulaeformis stands and Q. aliena var. acuteserrata stands. Each point is the average value of 12 replicates. 
Fig. 4 - Litter water-absorption rate of (a) non-decomposed litter (OL) and (b) semi-decomposed litter (OF) of $P$. tabulaeformis and Q. aliena var. acuteserrata. Each point is the average value of 12 replicates.

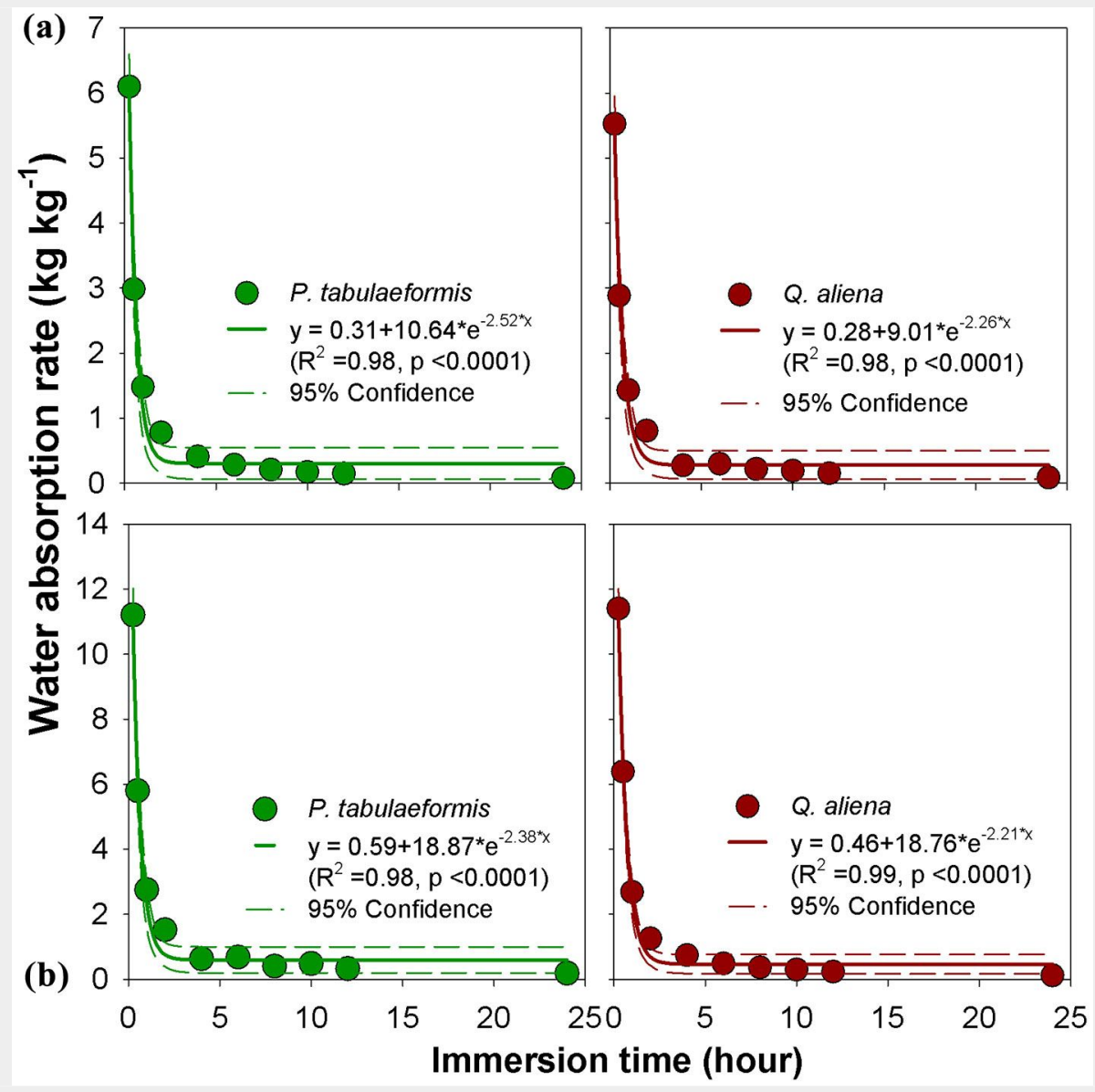

formis, not significantly different from the value observed for Q. aliena (212.76 \pm $24.64 \%$ ) The $R_{m}$ of the OF for P. tabulaeformis was $386.80 \pm 99.33 \%$, significantly higher than $294.53 \pm 69.21 \%$ for Q. aliena ( $p$ $<0.05$ - Fig. 5a).

The total water retention capacity $\left(W_{\mathrm{m}}\right)$ of the OL for $P$. tabulaeformis was $22.35 \pm$ $8.68 \mathrm{Mg} \mathrm{ha}{ }^{-1}$, which was not significantly different from $14.82 \pm 4.78 \mathrm{Mg} \mathrm{ha}^{-1}$ for Q. aliena. The $W_{m}$ of the OF was $65.87 \pm 32.66$ $\mathrm{Mg} \mathrm{ha}^{-1}$ for $\mathrm{P}$. tabulaeformis, significantly higher than $26.91 \pm 12.38 \mathrm{Mg}^{-1}$ observed for Q. aliena (Fig. 5b). The $W_{m}$ of the entire litter layer for $P$. tabulaeformis was $88.22 \pm$ $38.24 \mathrm{Mg} \mathrm{ha}^{-1}$, which was nearly two times the value of $41.74 \pm 12.63 \mathrm{Mg} \mathrm{ha}^{-1} \mathrm{~W}_{\mathrm{m}}$ for $\mathrm{Q}$. aliena (Fig. 5b).
The maximum water interception capacity $\left(W_{i}\right)$ of the OL was $15.82 \pm 5.96 \mathrm{Mg} \mathrm{ha}^{-1}$ for P. tabulaeformis, which was not significantly different from $11.52 \pm 4.40 \mathrm{Mg} \mathrm{ha}^{-1}$ for Q. aliena. The $W_{i}$ of the OF was $37.53 \pm$ $21.86 \mathrm{Mg} \mathrm{ha}^{-1}$ for $P$. tabulaeformis, which was significantly higher than the $W_{i}$ detected for the OF layer in Q. aliena (18.39 \pm $8.50 \mathrm{Mg} \mathrm{ha}^{-1}-$ Fig. 5C).
Fig. 5 - (a) Maximum water-holding capacity $\left(R_{\mathrm{m}}, \%\right),(\mathrm{b})$ maximum water retention capacity $\left(\mathrm{W}_{\mathrm{m}}, \mathrm{T}_{\mathrm{T}} \mathrm{C}^{-2}\right)$, and $(\mathrm{c})$ maximum water interception capacity $\left(W_{i}, T a^{-2}\right)$ of the non-decomposed litter layer $(\mathrm{OL})$ and the semi-decomposed litter layer (OF) of P. tabulaeformis and Q. aliena var. acuteserrata. The vertical bar represents the standard error $(n=12)$. For each category, different capital letters indicate significant differences in the mean value between the two species.
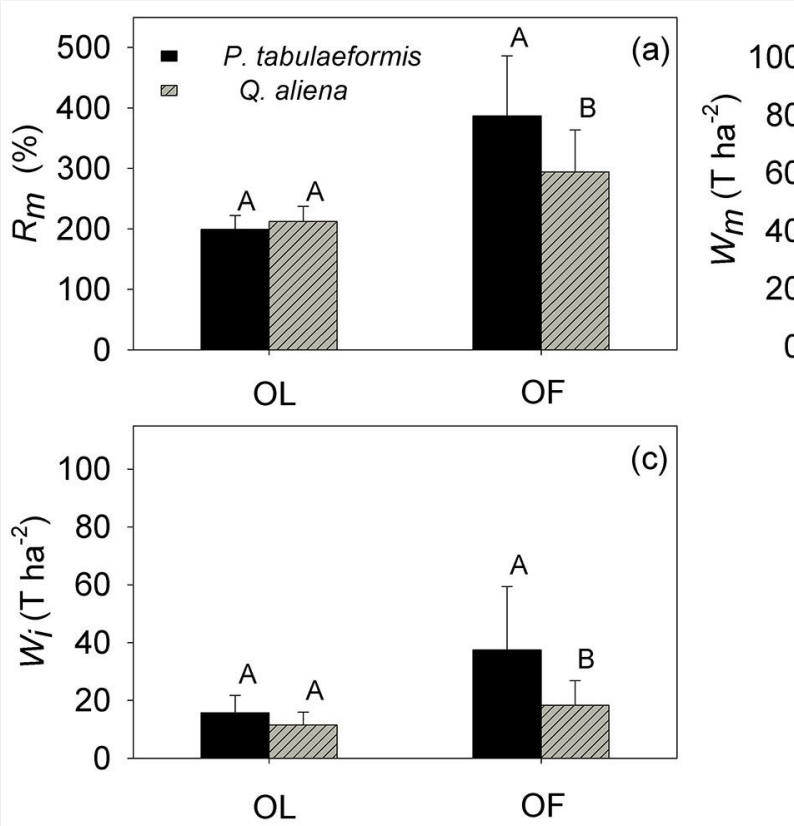


\section{Discussion}

P. tabulaeformis is an evergreen pine tree and its needles last for three to four years (Mu et al. 2015). The litter fall is concentrated between March and April and between November and December, with the litter fall from these two periods accounting for $50 \%$ of the annual litter fall. The needles account for more than $85 \%$ of the total litter. Contrastingly, the litter fall of the broadleaved Q. aliena is concentrated between September and November, with few leaves, dead branches and cones falling at other times (He et al. 2011). In this study, the $P$. tabulaeformis stands were at the near-mature stage and dead branches, cones, seeds, and flakes made up approximately $3 \%$ of the whole litter. These litter components are slower to decompose as compared with needles and leaves, and result in the accumulation of a thick litter layer and a relatively large litter mass (Shi et al. 2009, He et al. 2012). We found that he percentage of undergrowth shrub and herbaceous litter was relatively small, only $0.4 \%$ and $0.5 \%$ in P. tabulaeformis and Q. aliena stands, respectively (Tab. 3). The litter of Q. aliena contains a high carbohydrate content and low Klason lignin content, and decomposes more easily than that of $P$. tabulaeformis. The leaf litter decomposition half-life is $\mathbf{1 . 2 6}$ years for Q. aliena, much shorter than the 2.28 years reported for P. tabulaeformis (He et al. 2011, Han et al. 2012).

The litter layer is reported to substantially reduce the evaporation from mineral soil (Liu et al. 2011, Wang et al. 2013). Therefore, a thick litter layer or the conservation of the litter layer may favor moisture retention in shallow soil. On the other hand, the precipitation intercepted by the litter layer will mostly evaporate back into the atmosphere, and this loss can be substantial in a hot and dry climate (Acharya et al. 2017). The net effect of litter on forest surface water flux deserves further study in the studied climate conditions.

Gong et al. (2006) reported a rapid rise in the water content and a fast increase in the litter water-holding ratio at the onset of the water-immersion experiment in the laboratory. This is related to the low matrix water potential associated with drier litter. Our study showed that the absorption rate decreases exponentially when the litter becomes moist (Fig. 4). The litter in arid and semiarid ecosystems often has a low moisture content, whereby exhibits a great potential to retain the occurring rainfall. The semi-decomposed litter layer (OF) was able to quickly reach a high water-holding ratio of approximately 3 within an hour, which was higher than the non-decomposed litter layer (OL) at its holding capacity (Wang et al. 2004). This may be explained by the fact that the OF has a higher degree of fragmentation, a larger surface area per mass unit and is more conducive to water entrance (Liu et al. 2005). This characteristic is important in retaining water from high- intensity rainfall.

In this study, the OL of $P$. tabulaeformis stands showed a lower $R_{m}$ than that of $Q$. aliena stands, which is consistent with previous reports (Qi et al. 2011). This difference in hydrological properties is likely attributed to the difference in physical and chemical properties of the needles and leaves, since the non-decomposed needles of $P$. tabulaeformis have thicker cuticles and a higher oil content than the leaves of Q. aliena (Gong et al. 2011). Additionally, our results showed that the value of $R_{\mathrm{m}}$ for non-decomposed coniferous tree species was lower than that observed for broadleaved tree species in general (Zhang et al. 2010). In contrast, the $R_{m}$ for the OF of $P$. tabulaeformis was nearly twice as great as the $R_{m}$ for the semi-decomposed litter of $Q$. aliena. The OF of $Q$. aliena reaches its water-holding capacity quickly while it takes hours for the OF of P. tabulaeformis to reach its holding capacity. Further studies are needed to throw light on the biological and hydrological mechanisms underlying the above evidence, as well as to better understand whether such differences are either species-specific or more general between conifers and broadleaves.

While the $R_{\mathrm{m}}$ defines the effectiveness of unit mass litter in retaining water, ultimately the water retention capacity of the litter layer $\left(W_{m}\right)$ depends on the litter mass (Zhang et al. 2010, Li et al. 2013). Our study showed that the water-retention capacity of $P$. tabulaeformis is nearly two-fold that of Q. aliena as a result of greater mass and more effective OF. However, Zhang et al. (2010) reported a smaller water-retention capacity of the semi-decomposed OF layer as compared to the non-decomposed $\mathrm{OL}$ layer, and Li et al. (2013) showed a higher water retention capacity in broadleaved than in coniferous forest litter of co-occurring stands in other forest ecosystems. A comprehensive study is needed to systematically investigate litter characteristics and their hydrological properties across different climate regimes and forest ecosystems, also aiming to assess the latent heat transfer, the microclimate for microbes, and the carbon flux from forest litter.

The water interception capacity $\left(W_{\mathrm{i}}\right)$ of the litter is a hydrological property which sets the upper limit of precipitation loss to the litter layer for any given event. This value varies depending on the antecedent litter water content, which varies substantially under a hot and dry climate (Acharya et al. 2017). A simple conversion of $W_{i}$ obtained in this study suggests that the litter layer can theoretically intercept up to 53.35 $\mathrm{mm}$ of throughfall in $P$. tabulaeformis stands and up to $29.91 \mathrm{~mm}$ in Q. aliena stands (Fig. 5C). This provides a substantial capacity to minimize the splash erosion from high-intensity storms. Chen et al. (2008) reported that surface runoff rarely occurs until the rainfall is above $50 \mathrm{~mm}$ for the P. tabulaeformis forest in the Miyun District of Beijing. There is a little surface runoff in the forested area of this study; however, it is largely unknown whether $W_{i}$ will be reached in situ for a given storm. Recent development in the measurement of in situ litter water content may provide more realistic estimates of the rainfall interception by the litter (Wang et al. 2013, Acharya et al. 2017). Nevertheless, the $W_{i}$ value may give a useful indication of the maximum litter interception and a combination of both approaches may improve our estimation of water flux in the forest ground, which is important not only for the hydrological budget but also for an improved understanding of energy partitioning and microbe-driven carbon flux in forest ecosystems.

The $P$. tabulaeformis and Q. aliena mixed forest analyzed in this study is at a late successional stage for this climate zone, and is the result of forest harvesting carried out in the 1960s and the 1970s (Yu et al. 2013). From the perspective of water resource management, our results suggest that $P$. tabulaeformis stands have a dense litter layer suitable to intercept rainfall and buffer storm impact. The increase in litter mass along with the development of an overgrown canopy of $P$. tabulaeformis may be one of the aforementioned non-climate causes and can be partially responsible for the decreasing trend in the streamflow (Liu et al. 2012). P. tabulaeformis is an endemic species in northern China and will eventually out-compete $Q$. aliena at the mid-elevations of the Qinling Mountains (Zhang 1989).

The precipitation in the Qinling Mountains area is characterized by uneven seasonal distribution and large annual variation. The majority of rainfall is concentrated from May to October, accounting for more than $85 \%$ of the annual precipitation with frequent occurrence of heavy rains, torrential rains, and other extreme weather events. Moreover, the mountainous topographic features of this area are prone to geological disasters, including floods, mudslides and landslides (Chen et al. 2013). From the management perspective, a thick and dense litter layer may favor the delay and decrease in the formation of surface runoff, reducing the occurrence of geological disasters. Strategic removal of some unhealthy Q. aliena trees may promote $P$. tabulaeformis growth, thus improving litter layer characteristics. Conversely, in areas with low precipitation, such as the Loess Plateau, the rocky mountain area of North China and other areas, the thin litter layer of forest or savanna dominated by Q. aliena may be considered favorable to rainfall infiltration and potential streamflow enhancement. Additionally, the quantity and quality of litter affects the morphology and properties of soils as well as the nutrition of plants and soil heterotrophic organisms (llek et al. 2015).

The overgrown secondary forests on the Qinling Mountains are the result of the lack of management in the past, similar to the 
vast cypress and red cedar plantations in Japan (Kuraji 2012, Sun et al. 2014). The impact of overgrown plantations on the hydrologic budget and water quality requires further studies to sustain the multiple ecosystem services provided by forests (Sun et al. 2014, Komatsu \& Rappleye 2017).

\section{Conclusions}

The overgrowth of the mixed forests in the Qinling Mountains causes uncertainty on their current water-conservation function. We studied the structure and hydrologic properties of the litter layer in stands of the two dominant species, P. tabulaeformis and Q. aliena, finding significant differences between them. P. tabulaeformis stands have a much thicker semi-decomposed layer with a higher water-holding capacity than $Q$. aliena and is likely more effective in reducing overland flow and surface erosion. The selective removal of $Q$. aliena trees in overgrown mixed forests may promote the growth of $P$. tabulaeformis and improve water quality. However, the impact of Q. aliena removal on the total evapotranspiration of the forest is unknown. Further studies should aim at directly quantifying the impact of different scenarios of tree removal and their impact on water balance and water yield using an experimental watershed approach.

\section{Acknowledgments}

This study was supported by the Fundamental Research Funds for the Central Universities, Special Fund Programs of Basic Scientific Research of Northwest A\&F University (2452015043), the Natural Science Basic Research Program of Shaanxi Province of China (2014JM2-3029), Ph.D. research start-up foundation of Northwest A\&F University (Z109021505), National Natural Science Funds of China (Grant No. 31600580, 31670646). The Qinling National Forest Ecosystem Research Station provided all the background information and field equipment. This work was also supported by CFERN \& Beijing Techno Solutions Award Funds on excellent academic achievements. We thank Joseph Dale for language editing of the manuscript.

\section{References}

Acharya BS, Stebler E, Zou CB (2017). Monitoring litter interception of rainfall using leaf wetness sensor under controlled and field conditions. Hydrological Processes 31 (1): 240-249. - doi: 10.1002/hyp.11047

Bulcock HH, Jewitt GPW (2012). Field data collection and analysis of canopy and litter interception in commercial forest plantations in the KwaZulu-Natal Midlands, South Africa. Hydrology and Earth System Sciences 16 (10): 37173728. - doi: 10.5194/hess-16-3717-2012

Chang YJ, Cao J, Ma JW, Chen Q, Zhao L (2008). Water-holding characteristics of coniferous forest litters in west Qinling Mountains. Chinese Journal of Applied Ecology 19 (11): 2346-2351. [online] URL: http://europepmc.org/abstract/m ed/19238830
Chen LH, Yang XB, Lu SW, Sun QY, Xiao Y, Wang $Y$ (2008). Distribution of water consumption of Pinus tabulaeformis plantation in rocky mountain areas in northern China. Journal of Beijing Forestry University 30 (Suppl. 2): 182-187.

Chen SJ, Chen CG, Zou BC, Stebler E, Zhang SC, Hou L, Wang DX (2013). Application of Gash analytical model and parameterized Fan model to estimate canopy interception of a Chinese red pine forest. Journal of Forest Research 18 (4): 335-344. - doi: 10.1007/s10310-012-0364-z Dunkerley D (2000). Measuring interception loss and canopy storage in dryland vegetation: a brief review and evaluation of available research strategies. Hydrological Processes 14 (4): 669-678. - doi: 10.1002/(SICI)1099-1085(20 0003)14:4<669::AID-HYP965>3.0.CO;2-I

Gallart F, Llorens P (2003). Catchment management under environmental change: Impact of land cover change on water resources. Water International 28: 334-340. - doi: 10.1080/02508 060308691707

Gao R, Zhou GZ (2002). A study on water-holding properties of litter layer for various major forest vegetation types in eastern mountainous region in Liaoning Province. Journal of Shenyang Agricultural University 0433 (2): 115-118. [online] URL: http://europepmc.org/abstract/ $\mathrm{cba} / 390464$

Gomyo M, Kuraji K (2016). Effect of the litter layer on runoff and evapotranspiration using the paired watershed method. Journal of Forest Research 21 (6): 306-313. - doi: 10.1007/s1031 0-016-0542-5

Gong GT, Chen JH, Li YQ, Zhang J, Zhu ZF, Zheng SW, Wu XX (2011). A comparative analysis of the hydrological effects of the four cypress stand types in Sichuan Basin. Acta Ecologica Sinica 31 (10): 2716-2726.

Gong W, Hu TX, Wang JY, Gong YB, Ran H (2006). Water holding characteristics of litter layer after natural evergreen broadleaved forest artificial regeneration in southern Sichuan province. Journal of Soil and Water Conservation 20 (3): 51-55. [online] URL: http://en.cnki. com.cn/Article_en/CJFDTotal-TRQS200603013. htm

Han QS, Ren HG, Liu JJ (2012). Contents and ratios of the decomposable and resistant plant material in the litters of the main trees in Qinling Mountains. Journal of Northwest Forestry University 27 (5): 6-10. - doi: 10.3969/j.issn.10017461.2012.05.02

He F, Wang DX, Lei RD (2011). Decomposition rate of four dominant tree species leaf litters in Qinling Huoditang forests. Chinese Journal of Ecology 30 (3): 521-526.

He Y, Ding GD, Liang WJ, Zang YT, Gao GL, An Y (2012). Influence of stand density on waterholding characteristics of litter layer. Journal of Northwest A\&F University (Natural Science Edition) 40 (4): 68-72. [online] URL: http://agris. fao.org/agris-search/search.do?recordID $=\mathrm{CN}_{2} \mathrm{O}$ 13000112

Ilek A, Kucza J, Szostek M (2015). The effect of stand species composition on water storage capacity of the organic layers of forest soils. European Journal of Forest Research 134: 187197. - doi: $10.1007 / \mathrm{s} 10342-014-0842-2$

Komatsu H, Rappleye J (2017). Incongruity between scientific knowledge and ordinary per- ceptions of nature: an ontological perspective for forest hydrology in Japan. Journal of Forest Research 4 (22): 75-82. - doi: 10.1080/13416979. 2017.1283977

Kuraji K (2012). Is forest blessing an illusion? Forest-human relation from the view point of a scientist. Kagaku Dojin, Tokyo, Japan.

Lei RD (1984). Study on water holding function of Pinus armandii forest in the Huoditang area of Qinling Mountains. Journal of Northwest Forestry University 1 (1): 19-34.

Levia DF, Bollinger WC, Hrabik RA (2005). Evaporation of intercepted precipitation from fruit litter of Liquidambar styraciflua L. (sweetgum) in a clearing as a function of meteorological conditions. International Journal of Biometeorology 49 (5): 325-331. - doi: 10.1007/s00484-004-0 245-z

Li X, Niu JZ, Xie BY (2013). Study on hydrological functions of litter layers in north China. PLoS ONE 8(7): e70328. - doi: 10.1371/journal.pone.00 70328

Liu SC, Duan WB, Zhao YS (2005). Water holding capacity of litter layer for various major forest types in Lianhua Lake reservoir area. Science of Soil and Water Conservation 3 (2): 81-86. [online] URL: http://en.cnki.com.cn/Article_en/ CJFDTOTAL-STBC200502016.htm

Liu YG, Liu CC, Li GQ, Wei YF, Liu YG, Guo K (2011). Litter mass of five Karst forests and their hydrological effects in Guizhou. Scientia Silvae Sinicae 47 (3): 82-88. [online] URL: http://en.cnki.com.cn/Article_en/CJFDTOTALLYKE201103013.htm

Liu X, Liu C, Luo Y, Zhang M, Xia J (2012). Dramatic decrease in streamflow from the headwater source in the central route of China's water diversion project: Climatic variation or human influence? Journal of Geophysical Research 117: Do6113. - doi: 10.1029/2011JD016879 Llorens P, Poch R, Latron J, Gallart F (1997). Rainfall interception by a Pinus sylvestris forest patch overgrown in a Mediterranean mountainous abandoned area. I. Monitoring design and results down to the event scale. Journal of Hydrology 199 (3-4): 331-345. - doi: 10.1016/Soo 22-1694(96)03334-3

Mu Y, Ren L, Hu X, Zhao Y, Li H, Lu H, Liu D (2015). Season-specific changes in telomere length and telomerase activity in Chinese pine (Pinus tabulaeformis Carr.). Russian Journal of Plant Physiology 62 (4): 487-493. - doi: 10.1134/ S1021443715040147

Neris J, Tejedor M, Rodriguez M, Fuentes J, Jiménez C (2013). Effect of forest floor characteristics on water repellency, infiltration, runoff and soil loss in Andisols of Tenerife (Canary Islands, Spain). Catena 108: 50-57. - doi: 10.1016/ j.catena.2012.04.011

Pan Y, Li X, Gong P, He C, Shi P, Pu R (2003). An integrative classification of vegetation in China based on NOAA AVHRR and vegetation-climate indices of the Holdridge life zone. International Journal of Remote Sensing 24 (5): 1009-1027. doi: $10.1080 / 01431160110115816$

Qi J, Shi Y, Yu XX, Zheng JK, Li HG (2011). Hydrological function of litters of the main tree species in Beijing mountainous area. Research of Soil and Water Conservation 18 (3): 73-77. [online] URL: http://en.cnki.com.cn/Article_en/CJF DTOTAL-STBY201103016.htm 
Sato Y, Kumagai T, Kume A, Otsuki K, Ogawa S (2004). Experimental analysis of moisture dynamics of litter layers-the effect of rainfall conditions and leaf shapes. Hydrological Processes 18 (16): 3007-3018. - doi: 10.1002/hyp.57 46

Schaap MG, Bouten W, Verstraten JM (1997) Forest floor water content dynamics in a Douglas fir stand. Journal of Hydrology 201(1-4): 367-383. - doi: 10.1016/S0022-1694(97)00047-4 Shi ZJ, Wang YH, Xu LH, Xiong W, Yu PT, Guo H, Zhang LY (2009). Hydrological functions of litter layer of typical forest types in the Liupan Mountains of Ningxia, northwestern China. Journal of Beijing Forestry University 31 (1): 9199. [online] URL: http://www.cabdirect.org/cab direct/abstract/20093193784

Sun X, Onda Y, Otsuki K, Kato H, Hirata A, Gomi T (2014). The effect of strip thinning on tree transpiration in a Japanese cypress (Chamaecyparis obtusa Endl.) plantation. Agricultural and Forest Meteorology 15 (197): 123-135. - doi: 10.1016/ j.agrformet.2014.06.011

Wang YQ, Wang YJ, Zhang HJ, Xia YP, Xiao JW, Wu Y (2004). Research on litter hydrology characteristic of typical vegetation in Jinyun Mountain in Chongqing city. Journal of Soil and Water Conservation 18 (3): 41-44.

Wang $\mathrm{C}$, Zhao $\mathrm{CY}, \mathrm{Xu} \mathrm{ZL}$, Wang $\mathrm{Y}$, Peng $\mathrm{HH}$ (2013). Effect of vegetation on soil water retention and storage in a semi-arid alpine forest catchment. Journal of Arid Land 5 (2): 207-219. doi: 10.1007/s40333-013-0151-5

Wen Y (2011). Construction of Qinling ecological demonstration area. Journal of Anhui Agricultural Science 39 (23): 14278-14280, 14284. [online] URL: http://en.cnki.com.cn/Article_en/CJF DTotal-AHNY201123142.htm

Yu F, Wang DX, Shi XX, Yi XF, Huang QP, Hu YN (2013). Effects of environmental factors on tree seedling regeneration in a pine-oak mixed forest in the Qinling Mountains, China. Journal of Mountain Science 10 (5): 845-853. - doi: 10.1007/ s11629-013-2548-1
Zhang YQ (1989). Shaaxi forest. Shaanxi Science and Technology press, Xi'an, China, pp.189-197. Zhang F, Peng ZD, An YX, Chen JQ, Ren YM (2010). Water-holding characteristics of the litter under main tree species plantations in Beijing Xishan Mountainous areas. Scientia Silvae Sinicae 46 (10): 6-14. [online] URL: http://en. cnki.com.cn/Article_en/CJFDTOTAL-LYKE20101 0002.htm

Zhang SL, Liang CP (2012). Effect of a native forest canopy on rainfall chemistry in China's Qinling Mountains. Environmental Earth Sciences 67 (5): 1503-1513. - doi: 10.1007/s12665-012-15942

Zou CB, Breshears DD, Newman BD, Wilcox BP, Gard MO, Rich PM (2008). Soil water dynamics under low- versus high-ponderosa pine tree density: ecohydrological functioning and restoration implications. Ecohydrology 1 (4): 309315. - doi: 10.1002/eco.17 